\section{Diagnostic Approach in the Hypertensive Child}

\section{MICHAEL J. DILLON}

\section{Renal Unit, Hospital for Sick Children and Department of Nephrology, Institute of Child Health, London, UK}

The extend to which investigation is warranted depends on the severity and the persistence of the hypertension and the circumstances in which it is detected. There are clearly important differences between mild hypertension identified incidentally in an asymptomatic child and severe hypertension observed in a patient with clinical symptoms related it. All children with sustained hypertension should undergo some evaluation but the question is how intensively should this be undertaken.

Borderline hypertension requires a careful history with particular emphasis on family history of hypertension and the use of drugs including the contraceptive pil1. Some simple additional investigations such as those outlinded in strategy $A$ maybe appropriate.

Mild to moderate hypertension will require more detailed evaluation with particular emphasis on renal disease which is the conmonest cause of secondary hypertension in childhood. This degree of hypertension would require strategies $A$ and $B$ at least.

Severe hypertension, namely blood pressure consistently well above the upper end of the normal range with or without target organ involvement would require strategies $A$ and $B$ with other more invasive investigations from within strategy $\mathrm{C}$ dependent on the initial results.

\section{Strategies of Investigation of Childhood Hypertension}

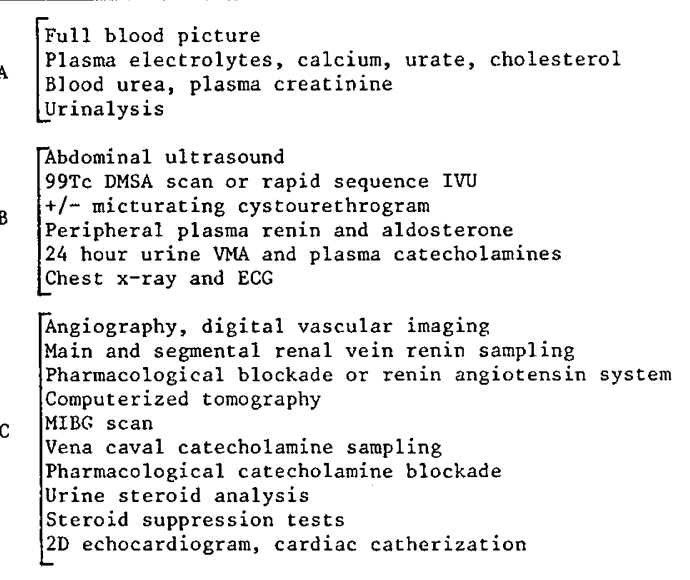

The particular value of peripheral plasma renin and catecholamine measurements, DMSA and MIBG scans, renal angiography, renal vein renin and vena caval catecholamine sampling is emphasized. Recently the oral captopril test to distinguish between renin dependent and other hypertensive states has proved to be useful in children. Measurements of red cell membrane

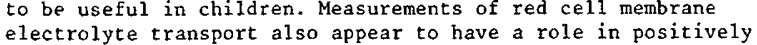
identifying children with essential as opposed to secondary hypertension.

Utilizing this approach a precise diagnosis can be established in the majority of hypertensive children.

\section{New Aspects in the Treatment of Renal Hypertension}

\section{KARL SCHÄRER, W. RASCHER, A.B. GRUSKIN}

Departments of Paediatrics, University of Heidelberg, FRG, and Wayne State University School of Medicine, Detroit, MI, USA

Recent advances in ant ihypertensive therapy of kidney disease are summarized in this report based on the experience given by participants of the Second Internaticnal Symposium on Hypertension in Children and Adolescents (Heidelberg/FRG, October 11-12, 1985). The report deals mainly with renovascular lesions and chronic renal fallure(CRF), with renovascular lesions and chronic renal fal by new techniques of revascularisation, intraluminal dilat at on and embollsation. In CRF medical therapy is best startep with a diuretic or a beta-adrenergic blocker, eventually added by a vasodllator and a centrally acting agent. More potent drugs (captotril, calcium antagonlsts) are More potent drugs (captotril, calclum pressure may avold the appearance of car trol of blood pressure may avold the appearance of cardiovascular complications and delay the rate of deteri oration of CRF. However, side effects by drugs remain a serlous problem. Under dialysis drug dosage can usually be reduced by increasing ultrafiltration. In general continuous peritoneal dialys is allows a better bloo pressure control than haemodialysis. Resistant cases are successfully treated by haemofiltration. After transplantation the therapeutic approach is varlable, accor ding to the eticlogy of hypertension (rejection or renal artery stenosis in graft, ischaemia in native kldneys, induced by corticosterolds or cyclosporin). 